\title{
Sea-level change from minutes to millennia: first meeting of IGCP Project 639 in Oman
}

\author{
J. Scott Padgett ${ }^{1}$, Simon E. Engelhart ${ }^{1 *}$, Gösta Hoffmann ${ }^{2,3}$, Alar Rosentau ${ }^{4}$, and Fengling $\mathrm{Yu}^{5}$ \\ ${ }^{1}$ Department of Geosciences, University of Rhode Island, Kingston, Rhode Island 02881, USA; *Corresponding author, \\ E-mail: engelhart@uri.edu \\ ${ }^{2}$ Applied Geosciences, German University of Technology in Oman, Muscat, PO Box 1816, Sultanate of Oman \\ ${ }^{3}$ Steinmann Institute, Department of Geology, Bonn University, D-53115 Bonn, Germany \\ ${ }^{4}$ Department of Geology, University of Tartu, 50090, Tartu, Estonia \\ ${ }^{5}$ State Key Laboratory of Marine Environmental Science, Xiamen University, Xiamen 361102, China
}

The Sultanate of Oman (Fig. 1) is an incredibly diverse geologic region with a plethora of cultural, geomorphic, and stratigraphic sealevel data sets and was, therefore, a brilliant location to kick-off the International Geoscience Program (IGCP) project 639 (http://www. sealevelchange.org) meetings. The United Nations Education, Scientific and Cultural Organization funded, IGCP 639 Project, "Coupling instrumental, historical, archaeological, and geological records of sealevel change over minutes to millennia", held its first meeting from November 9-14, 2016. The 2016 IGCP 639 project meeting was a multi-faceted conference that included a one-day workshop, two-day science symposium, and field-excursion components. Both the workshop and symposium sessions were held on the campus of German University of Technology in Oman, in Muscat, Oman and a three-day field excursion was conducted along Oman's northeastern coastline. Thanks to the commitment from the event organizers and enthusiastic involvement from attendees, the meeting was extremely successful and well acknowledged by all (Fig. 2a; http://sealevelchange.org/pdf/ igcpOman4.pdf).

Since the initiation of Project 61 led by Prof. Arthur L. Bloom in 1974, there has been an unbroken sequence of IGCP sea-level projects that have annually brought international scientists from related disciplines (e.g., historians, archaeologists, modellers, geodesists) together to share and discuss the latest findings and advancements in sea-level research. The participants have engaged in prolific discussions regarding the validity of local and/or regional sea-level curves and the development of standardized past sea-level reconstruction techniques (e.g., Bloom, 1977; Preuss, 1979; Shennan et al., 1987). Later projects shifted to include the study of the driving mechanisms of sea-level changes (e.g., Horton et al., 2009) as well as sea-level changes linked more directly to coastal hazards over shorter timescales such as those from coastal storms, earthquakes, and tsunami (e.g., Freymueller et al., 2015), and the introduction of an applied human aspect (e.g., Switzer et al., 2012). The IGCP 639 project continues the customs of the IGCP program, by aiming to serve as knowledge exchange platform for the development of integrated records of sealevel change and coastal hazards obtained from instrumental, historical, archaeological, and geological records.

The overarching goal of IGCP 639 is to develop new science-based assessments of coastal hazards and foster communication of these to coastal planners that incorporates both feedback from local communi- ties and the latest scientific information towards the development of safer and more resilient coastlines. To do so, IGCP 639 project meetings attract coastal researchers who share the common objective to develop best practice methodologies for assessing coastlines at risk of future inundation. At the IGCP 639 meetings researchers will share their experiences, approaches, and challenges of communicating information effectively while integrating local knowledge into coastal disaster mitigation efforts. Ultimately, IGCP 639 organizers and attendees seek to develop a framework that will lead to a robust coastal hazard tool-kit that describes the diverse range of coastal research methodologies, outlines communication approaches, as well as highlights community mitigation experiences that can be applied by various coastal communities globally. This kit will consider contributions to coastal

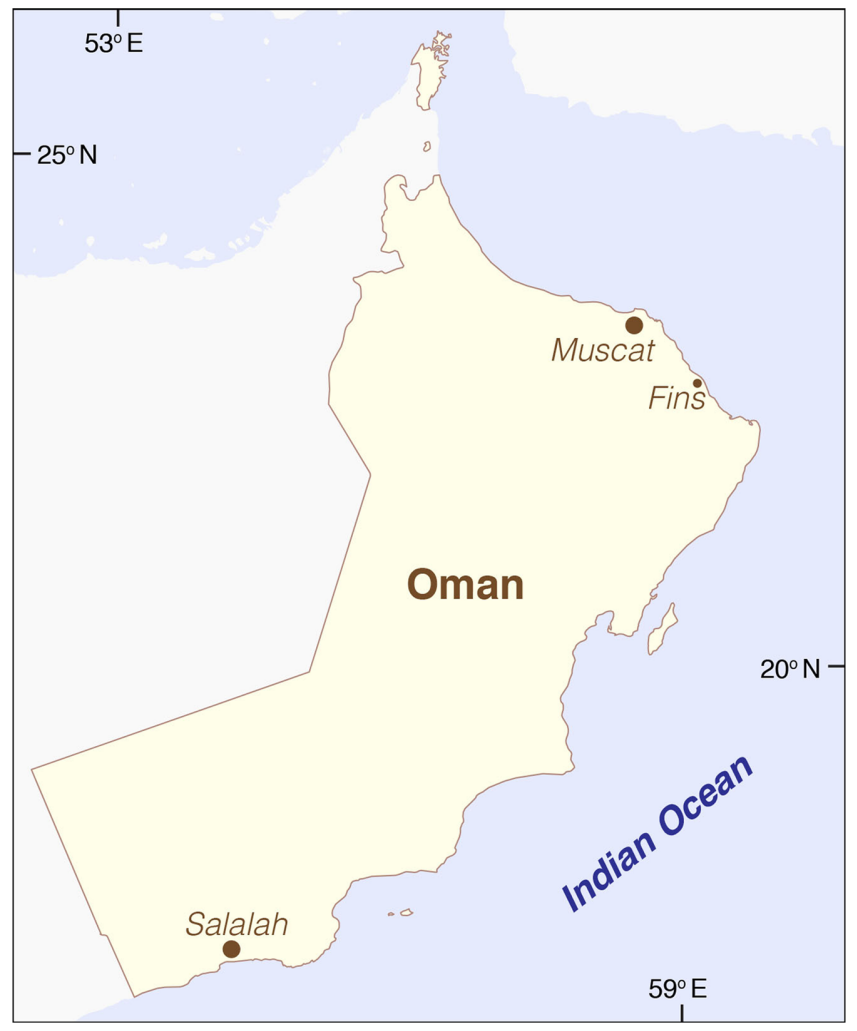

Figure 1. Location map of the Sultanate of Oman. 
hazards from many processes including, but not limited to, glacial isostatic adjustment (GIA), climate-related sea-level rise, and the magnitude and recurrence of extreme wave events.

Participants of IGCP 639 agree that the geoscientists' contribution to coastal disaster mitigation is to seek answers to the questions of recurrence intervals as well as definition of worst-case scenarios related to relative sea-level rise, coastal earthquakes, and extreme wave events. Advances are expected in holistic, high-resolution approaches where geoscientists collaborate with historians and archaeologists. For example, many IGCP researchers focus efforts on designing and improving appropriate coastal research methodologies such as microfossil transfer functions and developing sea-level index points, which can be used to precisely reconstruct relative sea-level changes based on geological and archaeological records, which can inform GIA models. Other IGCP researchers investigate the history of large coastal earthquakes (Wang et al., 2013) and the tsunamis they generate as well as developing tools to help aid in distinguishing the mechanisms for high-energy coastal deposits (e.g., storms or tsunami; Soria et al., 2017). It is anticipated that the combination of different records will lead to innovative approaches and new results that will help coastal communities better understand their potential risk.

Over 50 participants, including 14 female Omani undergraduate students who are interested in careers within this field, attended the workshop on techniques, successes, and challenges relevant to coastal hazards research. The workshop session involved introductions of important coastal research tools and several presentations that summarized unique aspects of sea level and coastal hazard research. Demonstrations of ground penetrating radar (GPR), real time kinematic global positioning systems (RTK-GPS) and terrestrial lidar scanning familiarized participants with different equipment and stimulated discussions regarding appropriate applications (Fig. 2c). Workshop presentation topics included; differentiating storm and tsunami deposits, examples of extreme wave events, tsunami modeling techniques, the application of diatoms in paleogeodesy and paleotsunami research, as well as examples of paleogeodetic research at several subduction zone coastal margins. The format of the workshop encouraged organizers and attendees to establish connections that were further cultivated during each proceeding session.

Following the workshop, thirty-eight international participants exchanged their latest insights of coastal hazards and integrations of methodologies related to coastal research conducted at sites including but not limited to Brazil, China, Colombia, India, Indonesia, Ireland, Netherlands, Oman, Pakistan, Philippines, South Africa, Turkey, and the United States of America. During the meeting, 29 oral and 14 poster presentations shared coastal hazard research that incorporates instrumental, historical, archaeological, and geological records over varying timescales. Three keynote presentations were given that addressed; 1) "Importance of sea-level research" by Prof. Ben Horton, 2) "Beach rock breakdown and preservation potential under sealevel rise" by Prof. Andrew Cooper, and 3) "The role of Holocene relative sea-level change in preserving records of subduction zone earthquakes" by Dr. Tina Dura. Prof. Horton explained that modern public communication of science information has evolved into a multi-directional conversational tone that includes many "experts" weighing-in. There are difficulties that face researchers regarding the dissemination of information clearly and effectively while also explaining how and why some pundits have misinterpreted the data and findings. Prof. Cooper introduced the concept of beach rocks and explained their potential utility for reconstructing past sea-level changes in areas without low-energy coastal deposits such as marshes or mangroves. Dr. Dura described why several subduction zones have different capabilities to record and preserve records of past seismic deformation and tsunami hazards. A spectrum of relative sea-level research and levels of expertise were well represented over varying career levels from undergraduates to world-renowned specialists. It is encouraging that researchers from around the globe took part in the three-sessions of the first IGCP 639 meeting (Fig. 2b).

Presentations during the symposium session addressed several significant topics of sea-level research such as differentiating a deposits' provenance, the incorporation of geo-archeology, as well as the role of transferring our scientific knowledge so that it can be used for informing the public. A notable sea-level research topic acknowledged during the symposia, are the difficulties that remain regarding the determination of a storm vs. tsunami deposit. Dr. Adam Switzer provided case study examples from Southeast Asia (e.g., Pilarczyk et al., 2016; Soria et al., 2017) that addressed recent advances towards this ongoing issue, which suggests heavy-metal mineralogy can not only define a composition signature of a deposit in question but could also potentially link a deposit to the derived source. The research also suggested that source location could differ depending on the local environment and on the transportation process (storm vs. tsunami). In some cases due to difficulties associated with many landscapes' ability to archive geological records of sea level change over the Holocene the sea-level research community sometimes turns to geo-archeology. In this regard, Dr. Martin Seeliger described an approach where he utilized a drowned seawall from an abandoned fishing village in Turkey as a past sea level indicator. Dr. Seeliger presented a newly constructed late Holocene sea-level curve, which incorporated both biogenic and anthropogenic sea-level indicators for the Bay of Elaia, Turkey (Seeliger et al., 2017). Also of note and in respect to outreach, it is critically important for the sea-level research community to appropriately inform public discourse and understanding of relative sea-level changes. In the first keynote presentation, Prof. Horton discussed recent complications that arose when a scientific accommodator attempted to oversimplify, and therefore mis-interpreted, a great deal of original scientific sea-level research in a 2016 Forbes opinion blog that "Sea level rise, which was occurring long before humans could be blamed, has not accelerated." Prof. Horton presented a deluge of recent research publications that he contributed towards (e.g., Engelhart et al., 2009; Kemp et al., 2011), which directly contrasts with the Forbes opinion blog assertion. Prof. Horton also referenced a research project conclusion, led by one of his former graduate students, which was cited by President Obama during his 2015 State of the Union Address "Our oceans are rising at the fastest rate in the last 2,000 years." By explaining the discrepancies between the original research and the accommodators' mistakes, Horton emphasized the scientific responsibility and importance of proper dissemination of information to the public audience. Discussions of these coastal research themes were not only encouraged during the symposia but were also promoted during the field excursion session, where several Omani examples were observed.

After the symposium, participants visited the northeastern Oman 

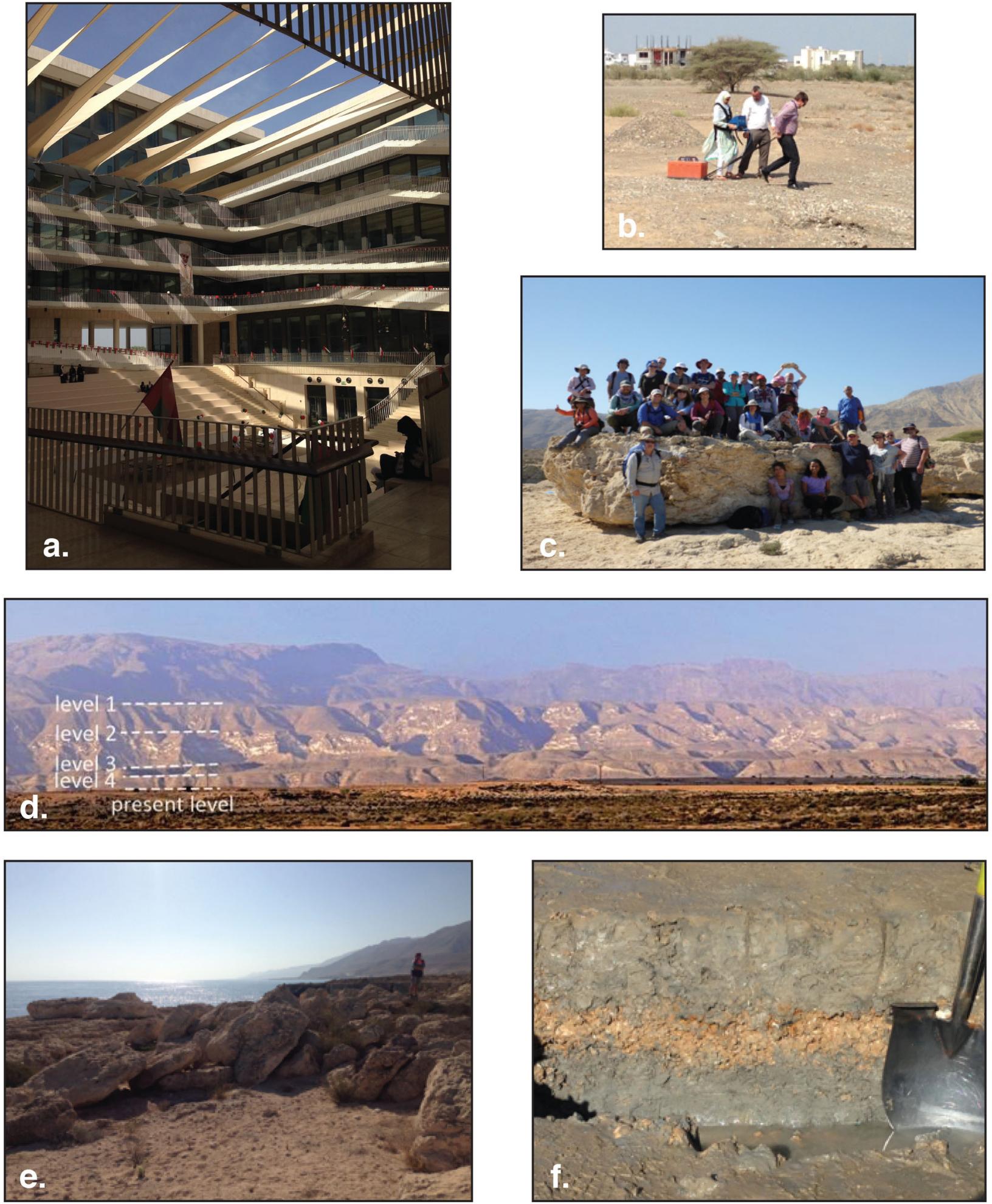

Figure 2. Pictures taken from the three-day field excursion of IGCP 639. (a) View from within GUtech administration building; (b) Demonstration of GPR during the workshop session; (c) Participants from the meeting on a mega clast boulder; (d) Uplifted marine terraces in Fins, Oman view south from camp; (e) Imbricated boulder clasts, eastern Fins, Oman; (f) Bivalve dominated tsunami-shell deposit, Sur Lagoon.

coastline, which has an extensive archive of past sea-level changes (Hoffman et al., 2013a). Along the coastal landscape of Fins, Oman is a set of uplifted marine terraces that document long-term $(\sim 700 \mathrm{ka})$ uplift where each terrace represents past sea-level highstands over the Late Pleistocene with dating based on ${ }^{230} \mathrm{Th} /{ }^{234} \mathrm{U}$ ratios of fossil corals found in growth position (Fig. 2d). Just east of Fins, extreme wave events are archived by imbricated mega clasts up to $\sim 120$ tons (Figs. $2 \mathrm{c}$ and e) that were derived from the adjacent coastal cliff (Hoffmann et al., 2013b). Within Sur Lagoon, Oman, intertidal stratigraphy of a laterally extensive and thick $(10-30 \mathrm{~cm})$ shell deposit can be found 
(Fig. 2f). Radiocarbon dating results on marine shell fossils, particle size distributions and interviews from local inhabitants suggests the deposit represents the 1945 tsunami (Donato et al., 2008; Donato et al., 2009; Hoffman et al., 2013a). At Ras al Hadd, Oman archeological evidences from three periods of occupation during the Bronze Age have been documented. There is also sedimentological evidence that this site was inundated by extreme wave events in-between the occupations. Locations visited during the field excursion encompassed applications of geological, archaeological and historical records each of which can be used to reconstruct past sea-level change.

The momentum developed at the first IGCP 639 meeting in Oman will, no-doubt, be carried over into the successive meetings. Reconvening organizers and participants will continue to advance their research that contributes towards the development of a coastal hazard tool-kit aimed towards the development of safer and more resilient coastlines globally. The second IGCP 639 meeting was recently held in Durban, South Africa from September $17^{\text {th }}-23^{\text {rd }} 2017$ and will be the subject of a future EPISODES meeting report.

\section{References}

Bloom, A.L., 1977, Atlas of Sea-Level Curves. IGCP Project 61: Sea-level project, Ithaca, $12 \mathrm{p}$.

Engelhart, S.E., Horton, B.P., Douglas, B.C., Peltier, W.R., and Törnqvist, T.E., 2009, Spatial variability of late Holocene and $20^{\text {th }}$ century sealevel rise along the Atlantic coast of the United States. Geology, v. 37, pp. 1115-1118.

Donato, S.V., Reinhardt, E.G., Boyce, J.I., Rothaus, R., and Vosmer, T., 2008, Identifying tsunami deposits using bivalve shell taphonomy. Geology, v. 36, pp. 199-202.

Donato, S.V., Reinhardt, E.G., Boyce, J.I., Pilarczyk, J.E., and Jupp, B.P., 2009, Particle-size distribution of inferred tsunami deposits in Sur Lagoon, Sultanate of Oman. Marine Geology, v. 257, pp. 54-64.

Freymueller, J.T., Hauessler, P.J., Horton, B.P., and Shennan, I., 2015, Megathrust earthquakes and sea-level change: a tribute to George Plafker. Quaternary Science Reviews, v. 113, pp. 1-2.

Hoffmann, G., Rupprechter, M., Balushi, N.A., Grützner, C., and Reicherter,
K., 2013, The impact of the 1945 Makran tsunami along the coastlines of the Arabian Sea (Northern Indian Ocean) - a review. Zeitschrift für Geomorphologie, Supplementary Issues, v. 57, pp. 257-277.

Hoffmann, G., Reicherter, K., Wiatr, T., Grützner, C., and Rausch, T., 2013, Block and boulder accumulations along the coastline between Fins and Sur (Sultanate of Oman): tsunamigenic remains? Natural hazards, v. 65 , pp. 851-873.

Horton, B.P., Long, A.J., and Donnelly, J.P., 2009, Quaternary ice sheet-ocean interactions and landscape responses. Quaternary Science Recviews, v. 28, pp. $1570-1572$.

Kemp, A.C., Horton, B.P., Donnelly, J.P., Mann, M.E., Vermeer, M., and Rahmstorf, S., 2011, Climate related sea-level variations over the past two millennia. Proceedings of the National Academy of Sciences, v. 108, pp. 11017-11022.

Pilarczyk, J.E., Horton, B.P., Soria, J.L.A., Switzer, A.D., Siringan, F., Fritz, H.M., Khan, N.S., Ildefonso, S., Doctor, A.A., and Garcia, M.L., 2016, Micropaleontology of the 2013 Typhoon Haiyan overwash sediments from the Leyte Gulf, Philippines. Sedimentary Geology, v. 339, pp. 104-114.

Preuss, H., 1979, Progress in computer evaluation of sea level data within the IGCP Project 61. International Symposium on Coastal Evolution in the Quaternary, 1978, Universidade Sao Paulo, Sao Paulo, pp. 104-134.

Seeliger, M., Pint, A., Frenzel, P., Feuser, S., Pirson, F., Riedesel, S., and Bruckner, H., 2017, Foraminifera as markers of Holocene sea-level fluctuations and water depth of ancient harbours - a case study from the Bay of Elaia (W Turkey). Palaeogeography, Palaeoclimatology, Palaeoecology, v. 482, pp. 17-29.

Soria, J.L.A., Switzer, A.D., Pilarczyk, J.E., Siringan, F.P., Khan, N.S., and Fritz, H.M., 2017, Typhoon Haiyan overwash sediments from Leyte Gulf coastlines show local spatial variations with hybrid storm and tsunami signatures. Sedimentary Geology, v. 358, pp. 121-138.

Shennan, I., 1987, Sea-level changes in the North Sea. In: Tooley, M.J., and Shennan, I. (Eds.), Sea-level Changes. Basil Blackwell, Oxford, pp. $109-151$.

Switzer, A.D., Sloss, C.R., Horton, B.P., and Zong, Y., 2012, Preparing for coastal change. Quaternary Science Reviews, v. 54, pp. 1-4.

Wang, P-L., Engelhart, S.E., Wang, K., Hawkes, A.D., Horton, B.P., Nelson, A.R., and Witter, R.C., 2013, Heterogeneous rupture in the great Cascadia earthquake of 1700 inferred from coastal subsidence estimates. Journal of Geophysical Research: Solid Earth, v. 118, pp. 1-14. 